\title{
Survey, investigation and repairing on concrete wall of waste water treatment building
}

\author{
Partogi H Simatupang ${ }^{1, *}$ and $J o n b i^{2}$ \\ ${ }^{1}$ Civil Engineering Department, Faculty of Science and Engineering, University of Nusa Cendana, \\ Kupang, Indonesia \\ ${ }^{2}$ Civil Engineering Department, Faculty of Engineering, Pancasila University, Jakarta, Indonesia
}

\begin{abstract}
Waste Water Treatment Building of the Multi National Company located in Cikande of Banten Province in Indonesia has experienced a poor function due to seepage and leakage on its reinforced concrete walls. The height of the reinforced concrete wall was 12 meters. This paper describes the surveys, investigations and repair conducted to overcome the seepage and leaks in the reinforced concrete walls. The feasibility of its concrete was investigated using Ultrasonic Pulse Velocity (UPV). The feasibility of the concrete was reviewed based on 2 (two) factors: (1) homogeneity and (2) crack depth. The result of the survey and investigation showed that the quality of homogeneity was enough and was pretty good and the average crack depth was about $\mathrm{h}=102,5 \mathrm{~mm}$. The method of repairing used was: (1) crack injection using epoxy, (2) leakage injection using cement modified polymer material and (2) waterproof coating using a cement-based coating. To prove the success of the repairing, pond testing was conducted for 14 days. Based on the test result, there was no leakage and seepage during the pond testing.
\end{abstract}

\section{Introduction}

The Waste Water Treatment Building (WWTB) of the Multinational Company located in Cikande, Banten will be reviewed in this paper. This building used the construction of reinforced concrete walls as high as 12 meters. After construction, there was seepage and leakage in its wall. The wall encountered deterioration such as the presence of honeycomb/segregation of concrete and cracks. Based on the construction report, this deterioration was observed as a result of uncontrolled slumps so that the slump value did not comply and the level of compaction was not sufficient at the time of casting.

The Waste Water Treatment Building is shown in Figure 1a. Meanwhile, construction of the wall is shown in Figure 1b. The layout of the building is given in Figure 2. Some seeped walls are shown in Figure 3. Figure 3 shows seepage on the wall with the surface area seepage (Figure 3.a) and spot seepage (Figure 3.b).

\footnotetext{
* Corresponding author: partogihsimatupang@gmail.com
} 


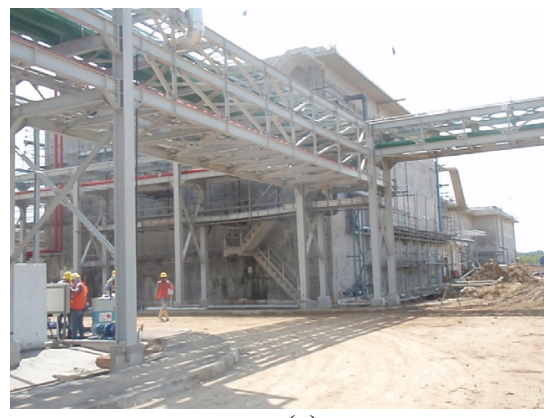

(a)

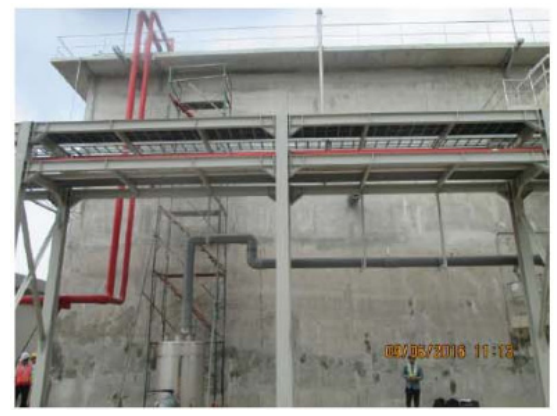

(b)

Fig. 1. Waste water treatment building: (a) condition of the plant and (b) the $12 \mathrm{~m}$ reinforced concrete wall.

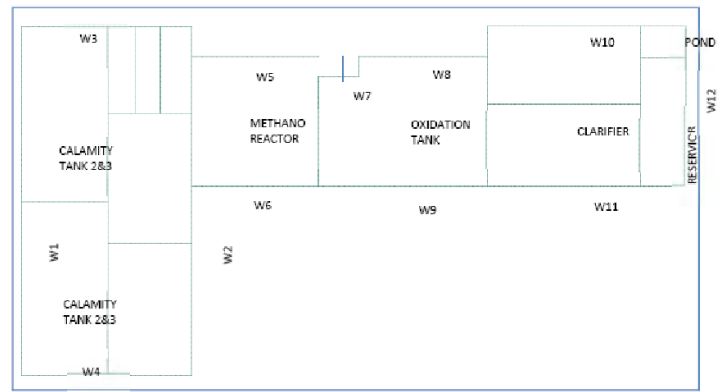

Fig. 2. Layout of waste water treatment building.

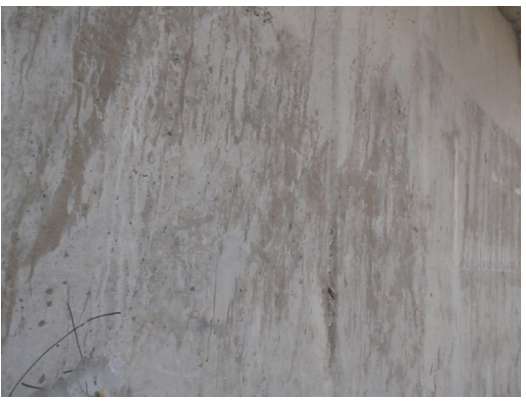

(a)

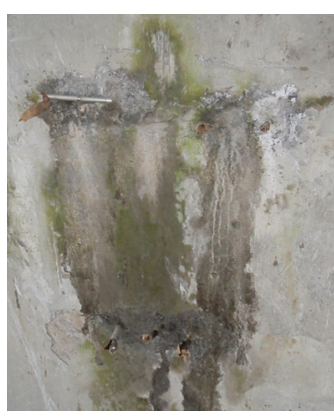

(b)

Fig. 3. Seepage on the wall: (a) surface area seepage on the wall W1 and (b) spot seepage on the wall W2.

Ultrasonic Pulse Velocity (UPV) testing is a Non-Destructive Test (NDT). Based on test findings, methods of structural repairing can be established. The results of non-destructive and destructive tests may be compared [1]. The wave velocity decreases by $1-3 \%$ per degree of substitution and the overall waves velocity increases with the material's age [2].

A non-destructive test (NDT) is a good alternative to measure concrete strength at times when destructive tests are not preferable [3]. The ultrasonic pulse velocity is higher when the concrete quality is better, in terms of density, uniformity, and homogeneity. As a result, the ultrasonic pulse velocity can be related to concrete compressive strength as well $[4,5,6]$.

This paper describes the survey, investigation and repairing conducted to overcome the problem. 


\section{Method}

The work steps performed are given in Figure 4. The work was preceded by a study of the legal report of construction. This work aims to get an idea of the things that happen during the construction stage, especially the concrete work. The next step is the survey. This survey aims to get an overall damage description, sketches of location and dimension of the damage. Then, it can be decided what investigation needs to be done.

Investigations that need to be done were crack depth testing and quality of concrete testing. The repairing method that needs to be done were: (1) crack injection, (2) leakage injection and (3) waterproof coating. After repairing was conducted, it was necessary to conduct a reliability testing on the repairing structure. Reliability testing conducted was the pond testing for 14 days with the intention of seeing the presence or absence of seepage that may occur.

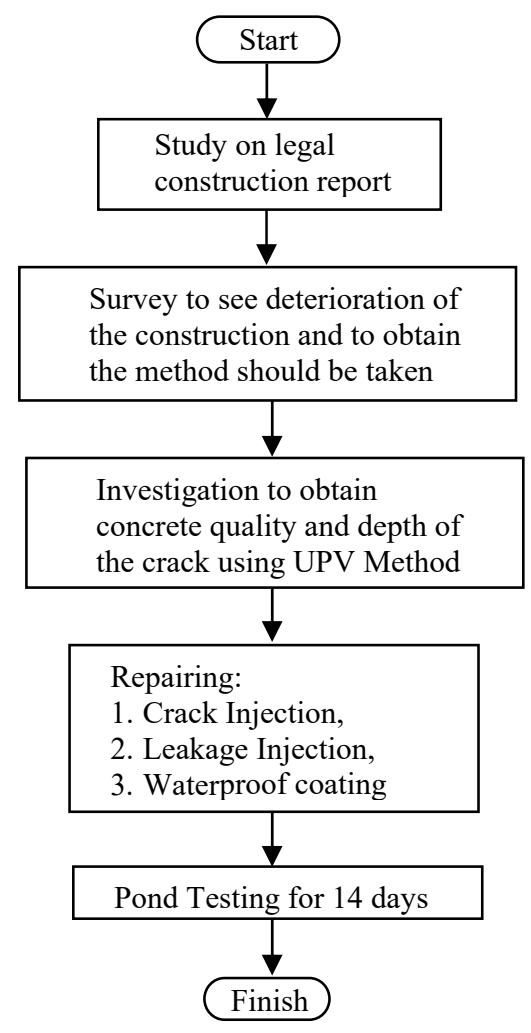

Fig. 4. Low chart of work.

\subsection{Investigation}

The investigation tests were: (1) Homogeneity test and (2) concrete crack depth measurement using UPV (Ultrasonic Pulse Velocity) method with Ultrasonic Testing Apparatus Proceq model Pundit Plus. Test methods performed are given in Figure 5. 


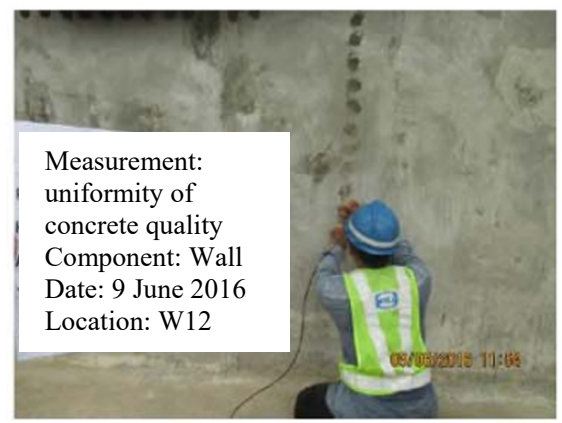

(a)

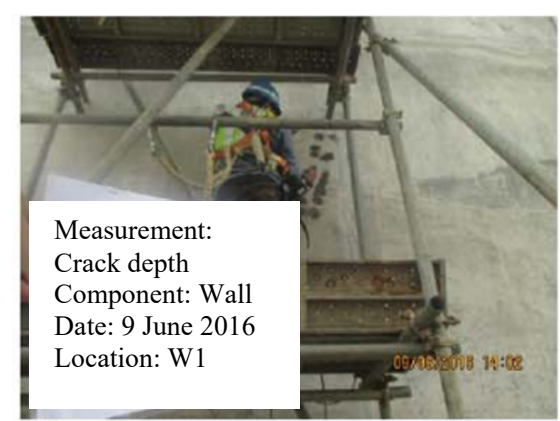

(b)

Fig. 5. UPV Testing: (a) UPV testing on concrete wall W12 (vertical) and (b) UPV testing on concrete wall W1 (for crack estimation).

Ultrasonic Pulse Velocity (UPV) Testing was measured by channelling the sound wave energy through the concrete with the transmitter point and receiver point. The pulses were transferred through an electrical impulse and travel times from the transmitter point (Transmitter) were recorded.

This test provided a qualitative indication of whether the crack was fully charged, partially filled or unfilled. The relationship of the velocity $(\mathrm{V})$, the length of the measurement path $\mathrm{L}$ and the propagation time (T) are given in Equation 1.

$$
\mathrm{V}=\mathrm{L} / \mathrm{T} \times 10^{6}
$$

where:

$$
\begin{aligned}
& \mathrm{V}=\text { velocity of pulse propagation }(\mathrm{km} / \mathrm{sec}), \\
& \mathrm{L}=\text { distance of measurement path }(\mathrm{m}), \\
& \mathrm{T}=\text { travel time of propagation }(\mathrm{sec})
\end{aligned}
$$

Meanwhile, the relationship between wave propagation velocity with the uniformity of concrete quality is given in Table 1. This test refers to SNI 03-4802-1998 (ASTM C597).

Table 1. The Relationship between velocity of pulse propagation with the uniformity of concrete quality (SNI 03-4802-1998).

\begin{tabular}{|c|c|}
\hline Velocity of pulse propagation $(\mathbf{V})(\mathbf{k m} / \mathbf{s e c})$ & uniformity of concrete quality \\
\hline $\mathrm{V}<2,13$ & less \\
\hline $2,13 \leq \mathrm{V}<3,05$ & enough \\
\hline $3,05 \leq \mathrm{V}<3,66$ & pretty good \\
\hline $3,66 \leq \mathrm{V}<4,57$ & good \\
\hline $\mathrm{V} \geq 4,57$ & very good \\
\hline
\end{tabular}

\subsection{Repairing}

Based on the results of the non-destructive test, all repair materials which have limitations and specifications must be considered. Then, the user should select the materials [6]. A previous study has successfully developed strong and durable repair materials. Furthermore, the use of local materials becomes the primary choice for repair materials [7]. Methods of repairing conducted were: (1) injection of cracks with Epoxy, (2) injection of leaks with cement modified polymer material, and (3) waterproofing coating with a cement-based material. 


\subsection{Testing on the repairing structure by pond testing}

To see the success of the repairing performed, the WWTB construction was tested by pond testing for 14 days. During the ponding process, a thorough observation of the concrete wall was conducted to see whether the seepage still occur or not.

\section{Result and discussion}

\subsection{Concrete quality and crack depth using UPV testing}

The concrete quality investigation result is summarized in Table 2. Based on Table 2, it can be seen that the quality of concrete applied on the walls of the reinforced concrete structures varies from the conditions of enough to pretty good.

Table 2. Resume of concrete quality.

\begin{tabular}{|c|c|c|c|}
\hline No & Location/Wall & $\mathbf{V ~}(\mathbf{k m} / \mathbf{s e c})$ & uniformity of concrete quality \\
\hline 1 & Vertical/wall W12 & 3,24 & pretty good \\
\hline 2 & Horizontal/wall W12 & 2,34 & enough \\
\hline 3 & Horizontal/wall W1 & 3,05 & pretty good \\
\hline 4 & Vertical/wall W1 & 3,32 & pretty good \\
\hline 5 & Vertical/wall W3 & 2,99 & enough \\
\hline
\end{tabular}

From the results of crack depth testing of wall W1, the average crack depth of 102.5 mm was obtained.

\subsection{Repairing}

Repair conducted is shown in Figure 6 to Figure 8. Crack injection stages are shown in Figure 6 . The stages were (1) cleaning the crack surface from dust and other dirt, (2) cutting the crack, (3) setting an injection nipple, (4) injecting the epoxy, and (5) cleaning the surface with a grinder. Meanwhile, leakage injection is shown in Figure 7. The stages were (1) cleaning the crack surface from dust and other dirt, (2) cutting the crack, (3) setting injection nipple, (4) injecting the cement modified polymer material, and (5) cleaning the surface with a grinder. The waterproof coating is shown in Figure 8. The stages were (1) cleaning the crack surface from dust and other dirt, (2) applying waterproof coating for 1 layer, and (3) applying waterproof coating for 2 layers perpendicularly.

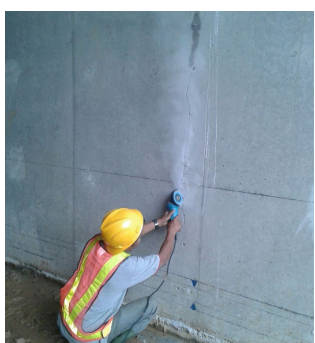

(a)

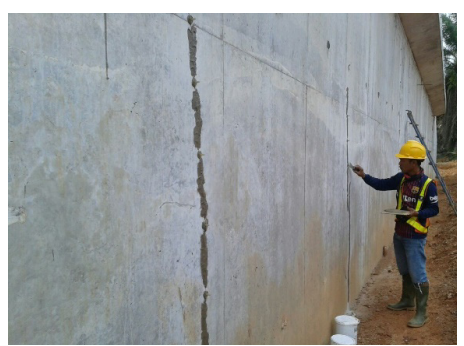

(b)

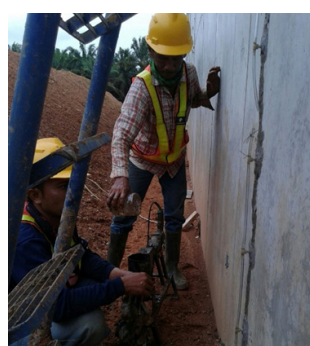

(c)

Fig. 6. Crack injection using epoxy: (a) cutting crack, (b) making injection nipple and (c) crack injection. 


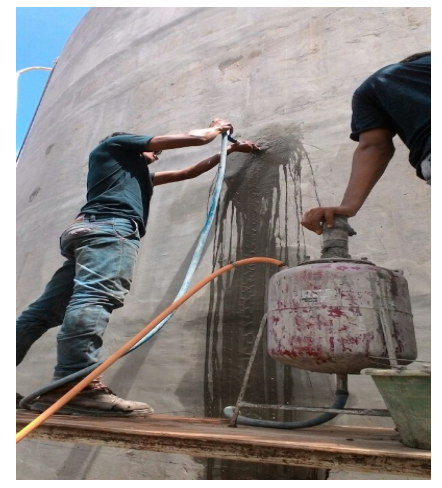

Fig. 7. Leakage injection using cement material with modified polymer.

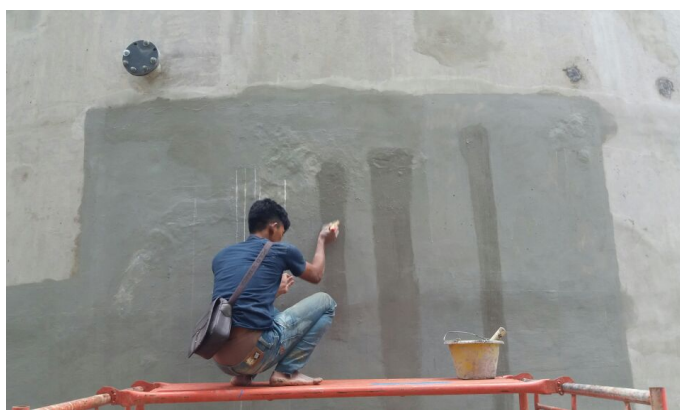

Fig. 8. Waterproof coating on the wall.

\subsection{Pond testing}

To prove the success of the repair, pond testing was conducted for 14 days as shown in Figure 9. Based on the test results, there was no leakage and seepage during the pond testing. WWTB was ready to use.
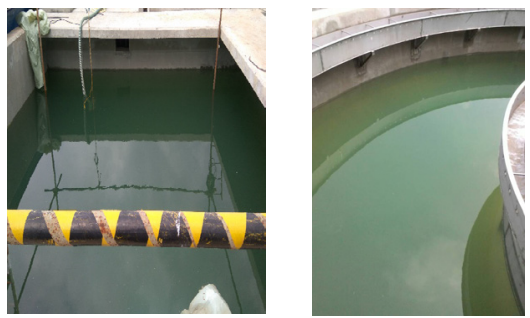

Fig. 9. Pond testing for 14 days.

\section{Conclusions}

Survey, investigation and repair work on WWTB concrete wall leakage has been presented. The leakage and seepage were caused by the inadequate quality of concrete work. An investigation conducted using UPV Testing showed that the quality of concrete was enough and had a pretty good quality with a crack depth of $102.5 \mathrm{~mm}$.

The repair methods using crack injection, leak injection and waterproof coatings were performed successfully. This was proved by the fact that there was no leakage and seepage during the pond testing for 14 days. 


\section{References}

1. S.Shankar, R.J. Hikmat. Journal of the Institute of Engineering, 10 (2014)

2. YS.Choi, SK.Baek, YT.Lee, SH.Kim, SU.Hong, Materials Research Innovations, 18 (2014)

3. YF Shih, YR Wang, KL Lin and CW Chen, Materials 8 (2005)

4. LR. Henao, JF.Gomez, and JC. Lopez-Aqui. ACI Materials Journal 109, (2014)

5. R. Pucinotti, Constr. Build. Mater, 75 (2015)

6. ACI 546.3R-06, Guide for the selection of Materials for the Repair of Concrete, American Concrete Institute,USA, (2015)

7. J.Jonbi, B. Hariandja, I.Imran, I.Pane, Applied Mechanics and Materials, 175-177 (2012) 